\title{
College English Teaching Constructed with Multi-intelligence Module
}

\author{
Wei Liu
}

School of Foreign Languages, Dalian Jiaotong University, Dalian, Liaoning, 116028

\begin{abstract}
:
College English teaching supported by multi-intelligences theory lays basis for the integration of teaching means and teaching content, which reflects college English curriculum reform adapted to the new concept proposed by the development of the times. In order to promote the integration of educational theory and curriculum and search the multiple entry point, this essay tries to introduce relevant theories and then based on case study, analyzes the operation of college English teaching on multi-intelligences platforms, aiming at laying the foundation for the further study of this teaching strategy.
\end{abstract}

Key words:

College English multi-intelligences module teaching

\section{多元智能模块构建大学英语教学}

\section{刘 巍}

\section{（大连交通大学 外语学院, 辽宁 大连 116028）}

\section{摘要:}

多元智能理论支持下的大学英 语教学是大学英语课程改革顺应时 代发展提出的新理念, 是整合教学手 段与教学内容的基础。为了推动教育 理论与学科课程的有机结合, 本文介 绍了相关理论要素, 然后以课例研究 为载体, 分析了基于多元智能平台开 展大学英语教学, 为深入研究这一教 学策略奠定基础。

\section{关键词:}

大学英语 多元智能模块 教学

\section{一. 多元智能理论与英语教学}

多元智能理论是由美国哈佛大 学的发展心理学家加德纳于 1983 年 在《智力的结构》一书中提出的。加 德纳认为智力是一种或一组个人解 决问题的能力, 或制造出在一种或多
种文化背景中被认为是价值的产品 的能力。智力是以组合的方式来进行 的, 每个人都是具有多种能力组合的 个体，而不是只拥有单一的用纸笔测 验可以测出的解答问题能力的个体。 每个人都同时拥有相对独立的八种 智力, 分别是: 言语一语言智力、逻 辑一数理智力、音乐一节奏智力、视 觉一空间智力、身体一动觉智力、自 知一自省智力、交往一交流智力、自 然智力。这些智力以不同方式、不同 程度有机地组合在一起。各种智力方 式都有自己个性化的学习风格。

加德纳识别不同职能的方法与语言 学家诺姆乔姆斯基提出的模块法是 一致的 ${ }^{11}$ 。

尽管加德纳刚开始时对于多元智能 的方法是否能够帮助外语教学持怀 疑态度, 他认为, 语言作为一种工具, 掌握它需要生活在一定环境中的机 会, 这个环境迫使学生使用这种语 
言; 或者需要进入语言实验室, 以便 接受强化训练。但是世界各地的外语 教师们 (包括将英语作为第二语言的 英语教师) 逐渐利用多元智能理论强 化了他们的外语教学。

如何在课堂教学活动过程中落 实和贯彻 “面向全体学生, 为学生的 全面发展和终身发展奠定基础”, 是 摆在我们面前亟待解决的问题。多元 智能充分考虑了每个学生的个体差 异, 提倡了因材施教和个性化教学, 倡导利用形式多样的课堂活动去调 动每个学生的积极参与, 反对用统一 僵化的标准来要求和评价每一个学 生, 体现了以人为本、以学生发展为 本的全新的教育理念。

二. 大学英语教学概述

成年人在进行二语学习的过程 中有两种相互衔接 (interface) 的 途径，一是习得（ acquisition）， 这是一种潜意识的构筑语言系统的 过程, 类似于儿童学习母语的过程; 二是学习( learning), 这是一种有 意识的学习过程, 学习者主动学习 总结相关的语言规则等, 并在输出过 程中不断地自我修正以达到正确使 用目的语。二语运用的流利程度取决 于语言的习得而不是学习。因此, 成 年人要想达到流利运用就必须主要 依靠二语习得。大学英语教学由语言 教师担纲授课, 目的主要在于提高 学生语言水平。教材主要围绕与某个 特定主题有关的话题, 或是覆盖某 一综合主题或内容。各类主题构成了 课程单元, 选材要符合学生的需求, 能够激发学生的兴趣, 话题要符合 主题的需要, 在最大限度上实现通 过学习内容来提高学生的综合语言 水平。这种模式由于操作简单易行, 对学生语言水平要求较低而常被采 用。国内新版的大学英语教材每个单 元都围绕某个特定主题编排, 选材符 合学生的需求, 能够激发学生的兴 趣, 每一单元的话题符合主题的需
要, 可以在最大限度上实现通过学习 主题内容来提高学生的综合语言水 平 $\mathbf{2} 2 \mathbf{2}$

三. 构建多元切入点实现大学英语教 学新模式

在大学英语教学中进行多元智 能活动设计时, 摒弃原来只操练英语 的教学知识点, 能够对学生的多种智 力一视同仁, 在设计思想上把多种智 力放在同等重要的地位上, 设计出发 展学生多种智能的活动, 使学生能够 较好地运用并发展自己的每一种智 力。尊重学生的个别差异, 树立正确 的学生观。如现在的大学英语教材注 重单元模块教学, 教师在介绍基本背 景知识后, 提供一些包括语言, 数理 逻辑, 视觉空间, 认识自然, 身体运 动, 音乐等智能的课堂或课外活动, 让学生选择。教师提供的活动时也必 须尊重学生的兴趣和爱好, 使得学生 可以以自己喜欢的方式方法去进行 英语活动。经过这样一个过程, 使所 有的学生都能认识到自己的智力弱 项和强项, 并寻找突破口, 帮助学生 将优势智能的特点迁移到弱项智能 中去, 开发和提高弱势智能的水平智 能组合水平提高 ${ }^{31}$ 。在多元智能课堂 中, 教师除适当讲解外, 多种方法并 用。如: 在英语教学中, 教师借助大 量可视化手段, 提供生动的画面和视 觉享受, 基于网络, 基于学习共同体 的学习, 甚至让学生离开座位寻找自 己的 “伙伴”, 进行教学, 达到人际 交往的充分发展 ${ }^{\mathbf{4}}$ 。在英语课文教学 中, 让学生通过讲故事, 多媒体演示 说明, 角色扮演的艺术活动, 游戏和 展示, 甚至通过现存的问题 (从哪里 来? 如何发展的? 事情的将来?) 掌 握学习内容。总之, 教师根据教学内 容和教育对象的不同, 采用多样化的 教学活动设计, 使学生能够用他们自 己所理解的方式去获取知识, 给予每 个学生以最大限度的发展机会。由此 可见, 多元智能理论不仅反映了教育 
目的, 而且为学生个性化发展提供了 教学工具。这对于教尽可能地了解每 个学生的特点, 针对教学对象实施个 性化教学具有重要的意义 ${ }^{551}$ 。

每个学生会以不同的方式学习, 表现不同的智能结构和倾向。如果我 们坚持要所有学生用同样的方式学 习相同的内容, 就会摧毁多元智能这 一伟大的理论。但是, 对于每班至少 有 50 名学生的教师来说, 因材施教 的前景显得非常渺茫。教师只能试图 在课堂教学中包含尽可能多的大量 内容, 根据多元智能理论的观点, 逐 渐提高教学效率。任何丰富的主题, 都可以通过至少 7 种不同的方式来 切入。这 7 个方式差不多与多元智能 相一致。我们可以将某个主题设想成 有 7 个切入点（入口）的房间。现在 让我们逐个研究这 7 个切入点或方 式, 举例说明每个切入点怎样用于处 理所要教学的主题-一西方的民主 制度。

第一, 运用叙述切入点或方式的时 候, 教师首先介绍与所要学习的概念 有关的故事, 结合叙述进行讲解, 如 古希腊民主的出现和美国宪法政府 的起源。

第二, 运用逻辑切入点或方式的时 候, 学生可以通过有组织的讨论学习 有关概念, 如 “民主” 是管理民众的 政府的一种形式, 或者是民众在做出 决定时适时地选出的代表。

第三, 量化切入点或方式处理与数字 有关的量和关系。如对于议会选举模 式的考察, 能够搞清楚民主政体是怎 样运作的, 或者是怎样陷入困境的。 第四, 基本原理或存在切入点检验某 一概念的哲学或术语的内涵。这种方 法被证明非常适合喜欢提出基本问 题的人。此方法用于西方民主政治主 题教学时, 可以思索民主这个字眼本 质上的意义、相对于其他制度的民主 制度与政府的关系、人们放弃专制而 选择民主制度的原因等问题。
第五, 让我们再来看美学途径, 有些 学生喜欢以艺术的方法来对待生活 体验。这种方法强调的重点, 就在于 吸引这些学生敏感的和表面的特征。 在西方民主政治讲解时, 可以让学生 聆听不同特征的音乐演奏, 如将合作 演出的四重奏和由一个人指挥的管 弦乐队进行对比。

第六个切入点就是经验途径, 一些学 生极擅长采用动手的方式学习, 喜欢 直接接触那些能够体现或表达某一 种观念的信息或素材。可以将一个班 分成若干组，模仿不同的政府机构制 定决策的过程, 通过和其他形式政府 的比较, 从正面和反面观察典型的民 主体制。

第七个也是最后一个是学生之间的 协作途径, 近来, 精心设计的小组学 习的优越性逐渐显现。那些愿意与其 他同学一起学习的学生, 特别适合于 以下形式的教学方法, 那就是集体研 究的课题、分组讨论或辩论、角色扮 演等活动---在这些活动中, 组内每 个学生都要做出独特的贡献。喜欢辩 论的学生, 可以重现当年赫胥黎和萨 缪尔 - 威尔福伯斯之间的争论。就像 记录的那样, 学生可以模仿不同形式 的民主---直接的、典型的、市镇议 会的---然后观察每一种选项的优点 和局限性。

根据以上模式, 教师应该能就一个主 题打开多扇窗户, 在上述教学案例 中, 教师不能仅仅靠定义、举例、讲 解词汇来介绍西方民主制度。他们能 够就同一主题提出若干不同的教学 方法。教师的作用, 就好像学生与课 程的中间人, 能够根据学生个人表现 出来的独特的学习模式, 经常注意到 那些能更有效地传达有关教学内容 的辅助器材, 如课文、影片、计算机 软件等并能尽量采用既有趣又有效 的方法来运用它们。多种切入点及方 式的教学的运用, 是转变学生错误观 念、偏见和陈旧学习方法的有力武 
器。教师综合运用不止一种方式切入 某一主题, 能吸引更多学生, 取得较 好的教学效果。

四. 实际操作中面临的挑战

构建大学英语教学多元切入点

的目的和重点是语言教学。其宗旨是 围绕某个特定主题或与某个特定主 题有关的话题组织教学。其运行机理 是想方设法让学生积极主动地参与 各种主题活动, 在参与活动的过程 中, 通过使用语言来实现语言教学的 目的。听、说、读、写等各项语言技 能在主题活动中得到综合运用, 通过 体验与实践、参与与评论以及归纳、 论述、讨论、辩论、展示、表演、娱 乐等形式习得语言 ${ }^{\mathbf{6} 1}$ 。教学的展开要 求教师英语口语好、交流能力强。而 我国大学英语公共课教学的绝大多 数情况是中国教师给中国学生用英 语授课, 即绝大多数情况下, 教师授 课用的不是其母语而是其外语。目 前, 虽然说让我国英语教师普遍达到 较高语言素质还不太现实, 但大学英 语公共课教师绝大多数能够达到该 要求 ${ }^{771}$ 。出于全面考虑, 建议CBI的 教师安排遵循如下两点: (1) 有条件 的院校可聘请英语外教负责英语公 共课的主题模式教学环节;（2）多种 教学模式结合使用, 安排交流能力 强、英语口语好的本国教师进行新模 式教学。鉴于主题模式和内容操练这 些互补性特征, 可将师生根据其不同 的特点进行分类匹配, 进而采用相适 应的教学模式。如: 在教学实践过程 中可以安排活动组织能力强、英语口 语好的教师教授思维活跃的进取型 学生 (如市场营销、工商管理等专业 的学生), 安排口语相对较差而又熟 悉语法结构教学法的教师教授思维 严谨、循规蹈矩型学生 (如机械、会 计专业的学生)。因各高校师生具体 情况千差万别, 不可一概而论, 上述 匹配只是按照笔者所在学校的师生 特点提出的建议。

\section{五. 结语}

当代教学改革正努力为大学英 语教学探索综合高效的教学模式，虽 然以多元智能模块为导向, 结合二语 习得理论框架的大学英语教学改革 才刚刚起步，还面临诸多挑战和困 难, 但我们已经上路, 以多元智能为 理论平台, 吸纳众多的教学方法和模 式，设计出一个综合完备的模式系统 只是保障新一轮教改成功的一个方 面。多元智能理念下的新模式虽是大 学英语教学改革的历史发展趋势, 但 新模式的成功实施需要社会和学校 的环境条件，需要师生和管理者的协 同合作，涉及多种教学资源和管理资 源的重新配置, 但我们坚信, 这种全 新的教学模式具有光明的前景！

\section{参考文献:}

[ 1] Gardner, H. (1983/2003). Frames of mind. The theory of multiple intelligences.New York: BasicBooks.

[ 2] Gardner, H. (1993). Multiple intelligences: The theory in practice.New York: BasicBooks.

[ 3] Grabe, W. \& Stroller, F. Content based instruction: Research foundations $[\mathrm{A}]$. In M. A. Snow \&Brinton D. ( eds. ) . The Content-based Classroom: Perspectives on Integrating Language and Content $[\mathrm{C}]$. New York: Longman, 1997: 69-72.

[4] Grabe,W,Stroller,F. Content-based instruction:Research foundations[A].New York:Longman,1997:78-81.

[5] Krahnke,K,J. Approaches to Syllabus Design for Foreign Language Teaching[M].New Jersey:Prentice-Hall,Inc,1987:114.

[6] Krashen S. Principles and Practice in Second Language Acquisition[M].Oxford:Pergamon Press,1982:112.

[7]Leaver,B.L,Stryker,S.B. Content-based instruction for foreign language classrooms $[\mathbf{J}]$.Foreign Language 